AGRICULTURE AND BIOLOGY JOURNAL OF NORTH AMERICA

ISSN Print: 2151-7517, ISSN Online: 2151-7525, doi:10.5251/abjna.2011.2.4.687.692

(C) 2011, ScienceHu $\beta$, http://www.scihub.org/ABJNA

\title{
Evaluation of fried edible oil and determination of trace elements content by FAAS
}

\author{
Mohamed G. Megahed ${ }^{1 *}$, El-Shahat H. A. Nashy ${ }^{2}$ and Emad A. Al-Ashkar ${ }^{3}$ \\ ${ }^{1}$ Fats and Oils Department, \\ ${ }^{2}$ Chemistry of Tanning Materials and Leather Technology Department, \\ ${ }^{3}$ Spectroscopy Department, Physics Division, National Research Centre, Dokki, Cairo, \\ Egypt. \\ *Corresponding author; Mohamed G. Megahed, dr mgmegahed@hotmail.com
}

\begin{abstract}
Edible oils form an essential part of our daily diet. Edible oils are derived from a wide variety of plants and plant seeds and are used in many aspects of domestic and world-wide food production. Once the oil has been extracted from a plant seed, it is refined as needed for use in foods such as salad dressings, margarine, shortenings, snack foods and frying oil .Although the overall quality of the product is generally defined by its culinary benefits, the inorganic content of these oils has a very important role in terms of food safety and general product longevity. Trace elements in edible oils can act as autoxidation accelerators, altering the flavor and quality of the product over time. In Egypt home kitchen and most restaurants use edible oils for frying of many different kinds of foods. Edible oils resulting from frying processes were characterized via fatty acids composition and chemical characteristics (Acid value, peroxide value, iodine value, saponification value, unsap. matter and ester value). Spectroscopic analysis (FT-IR) was used to study the change in chemical structure of oil by frying oxidation process. The trace elements content were determined by Flame Atomic Absorption Spectrometry (FAAS). The concentration of trace elements are increased after frying by about two folds. The oil before and after frying was evaluated.
\end{abstract}

Keywords: Edible oil, Fried oil, Chemical characteristics, Fatty acid composition, FT-IR, FAAS, Trace elements.

\section{INTRODUCTION}

Edible oils are extracted and processed world-wide and hence are important domestic and international commodities. Edible oils are very important food for word. The human body uses oils and fats in the diet for three purposes, as an energy source, as a structural component and to make powerful biological regulators. Oils and fats also play an important role in metabolic reactions in the human body [1].

Vegetable oils are beneficial and popular due to their cholesterol-lowering effect. In contrast to animal fats, which are predominantly saturated and hence do not react readily with other chemicals, especially oxygen, unsaturated vegetable oils are more reactive $[2,3]$. Vegetable oils are essential in global nutrition depending on the regional conditions, a variety of oils are produced in different qualities [4].

These oils are used in many aspects of food production such as baking, frying, for the manufacture of margarine, snack foods and salad oil products. Vegetable oils have naturally occurring high contents of phosphorus (in the form of phospholipids), calcium, magnesium and contain traces of other elements like iron and copper. Significant concentrations of these elements and substances in the final product can affect flavor, color and stability. To improve product quality, these substances are removed during the refining process [5]. Edible oils form an essential part of our daily diet. They are used in their native form for hightemperature cooking (for example, frying); as an ingredient for texture, flavor, and nutritional improvers; and as flavor carriers for other ingredients. Edible oils also have very wide usage as processed food-stuff. For example, in their hydrogenated form it is used as nondairy spreads and food additives. In their processed form, they are also gaining increased usage as a renewable bio-fuel [6].

Although the overall quality of the product is generally 
defined by its culinary benefits, the inorganic content (in trace level) of these oils has a very important role in terms of food safety and general product longevity. The mechanisms whereby inorganic constituents are incorporated into the oil include the natural uptake and accumulation of trace element by the plant and addition or adulteration at some point. Trace elements may also reach oils as contamination during harvesting / processing (for example, from foreign bodies during harvesting or wear metals in the press). Beside the obvious importance of monitoring these elements for safety or nutritional reasons, it has been reported [7] that some trace elements can act as auto-oxidation accelerators, altering the flavor and quality of the product over time. Some traditional approaches to elemental analysis of these materials include inductively coupled plasma optical emission spectroscopy (ICPOES), atomic absorption spectrometry FAAS I GFAAS), and ion chromatography (IC) [8].

In Egypt, home kitchen and most frying restaurants use the edible oil for frying some foods, such as, potato, green bell, eggplant and "Falafel" which is considerably a popular food in Egypt.

The quality of edible oils is directly related to the concentration of trace metals [9]. Therefore, In this work, the oils before and after frying were evaluated through chemical characterization as well as fatty acid composition. For AAS determination of trace elements, samples were digested with inorganic acids to form an aqueous clear solution to eliminate the organic matrix.

\section{MATERIALS AND METHODS}

Materials: Edible oils supplied by Egyptian government are blending from two or more different kinds of vegetable oils (sunflower, sayabean, cotton seed oils, ...etc.).

- Edible oil samples before and after frying were collected from home kitchen uses.

- Chemicals used for different analysis of oil were fine grade and supplied by international companies (Merk, Germany and $\mathrm{BDH}$, England).

\section{Methods}

\section{Analysis of Oil before and after frying:}

Chemical characteristics: Edible oil before and after frying were analyzed for its chemical characteristics according to the American Oil
Chemists Society Methods, (AOCS, 1998) [10]. The acid value, peroxide value, saponification value, iodine value, ester value and unsaponifiable matters were measured according to the AOCS, 1996 [11].

Fatty acid composition: Fatty acid methyl esters of edible oil before and after frying were prepared by IUPAC standard methods (1987) [12], and according to A.O.C.S. method (no. Ce 1b-89) [13]. Determination of fatty acid composition was performed as described by Mitruke (1984) [14] using Hewlett Packard HP 5890 series II gas chromatography, equipped with flame ionization detector (FID), operated under the following conditions:

Detector, flame ionization (FID); column, capillary, $30.0 \mathrm{~m} \times 530 \mu \mathrm{m}, 1.0 \mu \mathrm{m}$ thickness, polyethylene glycol phase (INNO Wax); $\mathrm{N}_{2}$ with flow rate, $15 \mathrm{ml}$ per min with average velocity $89 \mathrm{~cm} / \mathrm{s}(8.2 \mathrm{psi}) ; \mathrm{H}_{2}$ flow rate, $30 \mathrm{ml}$ per min; air flow rate, $300 \mathrm{ml}$ per min; split ratio, 8:1, split flow, $120 \mathrm{ml}$ per min; gas saver, $20 \mathrm{ml}$ per min. Detector temperature, $280^{\circ} \mathrm{C}$; column temperature, $240^{\circ} \mathrm{C}$; injection temperature, $280{ }^{\circ} \mathrm{C}$. Temperature programming starting from $100{ }^{\circ} \mathrm{C}$ to reach a maximum of $240^{\circ} \mathrm{C}$ was used for eluting the fatty acid methyl esters. The identification of peaks was made as compared with chromatograms of standard fatty acids methyl esters (Sigma, USA).

FT-IR Analysis: The change in functional groups of oils were studied using FT-IR analysis, it was performed using Mattson 5000 FTIR,USA spectrophotometer with resolution $4 \mathrm{~cm}^{-1}$.

Samples Preparation (Digestion): Oil samples (50 g) were weighted to the nearest milligram on four digits balance (Sartorious). Sulfuric acid was added to the sample and mixed well before heating on a hot plate to confirm forming nearly dry sample. After heating for one hour on the hot plate, samples were heated in a muffle furnace at $600{ }^{\circ} \mathrm{C}$ for 6 hours to get mineral ash of the sample components. In this case, all the metallic elements in the sample are converted to oxides. The sample ash is dissolved in nitric acid (Merck, Analar) and double distilled water is added to be $50 \mathrm{ml}$ volume to form clear acidic aqueous solution ready for atomic absorption spectrometric measurements. In parallel to the investigated samples, a blank sample was prepared similar to the real samples.

Flame Atomic Absorption Spectrometry (FAAS): Quantitative analysis of trace elements were performed by Flame Atomic Absorption Spectrometer (FAAS) using Varian SpectrAA 220, Australia. The 
standard solution was supplied by Merck. Trace element determination of $\mathrm{Ca}, \mathrm{Cu}, \mathrm{Fe}, \mathrm{Zn}, \mathrm{Ni}, \mathrm{Cr}$ and $\mathrm{Pd}$ were carried out at the spectral lines $239.9 \mathrm{~nm}$, $324.7 \mathrm{~nm}, 248.3 \mathrm{~nm}, 213.9 \mathrm{~nm}, 232.0 \mathrm{~nm}, 357.9 \mathrm{~nm}$, and $217.0 \mathrm{~nm}$ respectively.

The standard sources for the investigated elements are hollow cathode discharge lamps made by Cathodeon, England. The fuel used for the flame is acetylene for the elements under investigation with oxidizing flame stoichiometry. No chemical interferences were measured while measuring the elements of interest in this work. The working standard solutions were freshly prepared and normal calibration graphs were constructed for each element with suitable standard samples according to the recommendations of the manufacturer of the instrument [15].

\section{RESULTS AND DISCUSSION}

Characterization of Oil: Chemical characteristics of edible oil before frying and after frying have been extensively investigated. The data of saponification values, iodine value, acid value, peroxide value, unsaponifiable matter and ester value are illustrated in Table (1).

Table 1: Chemical characteristics of edible oil before after frying.

\begin{tabular}{|c|c|c|}
\hline \multirow[b]{2}{*}{ Characteristics } & \multicolumn{2}{|c|}{ Edible Oil } \\
\hline & Before frying & After frying \\
\hline Saponification value, $\mathrm{mg} \mathrm{KOH} / \mathrm{g}$ oil & 191.2 & 190.4 \\
\hline Iodine value, $\mathrm{mg} \mathrm{I}_{2} / \mathrm{g}$ oil & 133.4 & 129.1 \\
\hline Acid value, $\mathrm{mg} \mathrm{KOH} / \mathrm{g}$ oil & 0.8 & 6.2 \\
\hline Peroxide value $\mathrm{m} \mathrm{Eq/Kg}$ & 4.6 & 9.3 \\
\hline Unsaponifiable matter (\%) & 1.4 & 2.3 \\
\hline Ester value, (S.V- A.V) mg KOH) /g oil & 190.4 & 184.2 \\
\hline
\end{tabular}

It can be noticed from table (1) that, saponification value of edible oil before and after frying were almost the same (191.2 and $190.4 \mathrm{mg} / \mathrm{g})$ respectively. On the other hand, the iodine value of edible oil before frying had higher value $(133.4 \mathrm{~g} / 100 \mathrm{~g})$ compared with that after frying $(129.1 \mathrm{~g} / 100 \mathrm{~g})$.

Also, it is clear from the obtained results that, both the acid and peroxide values of edible oil increased after frying $(6.2 \mathrm{mg} / \mathrm{g}$ and $9.3 \mathrm{mg} / \mathrm{g})$ compared with that before frying $(0.8 \mathrm{meq} / \mathrm{kg}$ and $4.6 \mathrm{meq} / \mathrm{kg})$ respectively, causing undesirable odor of oil sample after frying. It could be also noticed that unsaponifiable matters of oil after frying had slightly higher value $(2.3 \%)$ compared with that before frying $(1.4 \%)$. The obtained data indicated that the local fried edible oil has a high ratio of unsaturation centers and ester groups, while it has a low ratio of free fatty acids (difference between SP.V. and A.V). These results might be due to the effect of high frying temperature causing destruction of some glycerides [16].

Fatty Acid Composition: The fatty acid composition of oil is considered as its most useful chemical feature. Many of the chemical tests for oil identity or purity can be related to the fatty acid content of the oil [17]. Fatty acids composition of edible oil before and after frying is illustrated in Table (2).

Table: 2 Fatty acids composition of edible oil before and after frying.

\begin{tabular}{|c|c|c|}
\hline \multirow[b]{2}{*}{ Fatty acids (\%) } & \multicolumn{2}{|c|}{ Edible Oil } \\
\hline & Before frying & After frying \\
\hline \multicolumn{3}{|l|}{ Saturated fatty acids: } \\
\hline Myristic $\quad\left(\mathrm{C}_{14: 0}\right)$ & 0.63 & 0.60 \\
\hline Palmitic $\quad\left(\mathrm{C}_{16: 0}\right)$ & 7.50 & 10.27 \\
\hline Stearic $\quad\left(\mathrm{C}_{18: 0}\right)$ & 4.70 & 7.37 \\
\hline Arachidic $\left(\mathrm{C}_{20: 0}\right)$ & 1.20 & 1.18 \\
\hline Total: & 14.03 & 19.42 \\
\hline \multicolumn{3}{|c|}{ Unsaturated fatty acids: } \\
\hline Oleic $\quad\left(\mathrm{C}_{18: 1}\right)$ & 36.17 & 33.20 \\
\hline Linoleic $\quad\left(\mathrm{C}_{18: 2}\right)$ & 45.50 & 43.28 \\
\hline Linolenic $\left(\mathrm{C}_{18: 3}\right)$ & 4.30 & 4.10 \\
\hline Total: & 85.97 & 80.58 \\
\hline
\end{tabular}

Unsaturated fatty acids such as linoleic acid plays an important role in modulating human metabolism and consumers consider fatty acid composition to be one of the important parameters of nutritional quality. It can be seen from Table (2) that the fatty acids 
contents of edible oil before and after frying were $(14.30 \%$ and $19.42 \%)$ of saturated fatty acids, and (85.97\% and $80.58 \%)$ of unsaturated fatty acids, where the saturated : unsaturated ratio were (1: 6.13) and (1: 4.15) respectively.

Oleic acid constitutes more than $42.0 \%$ and $41.0 \%$ of the unsaturated fatty acids of edible oil before and after frying respectively, while palmitic acids show more than $7.0 \%$ and $10.0 \%$ of the total fatty acids, respectively. On the other hand linoleic acid forms more than $45.0 \%$ and $43.0 \%$ of the total fatty acids for edible oil both before and after frying, respectively. It is also clear from the obtained results that, the poly unsaturated fatty acid (linolenic, $\mathrm{C}_{18: 3}$ ) forms low percent $(4.30 \%$ \& $4.10 \%)$ of the total fatty acids composition for before and after frying, respectively.

Particularly, consumers are concerned with saturated/ unsaturated fatty acid ratio and special attention is on the essential fatty acid with emphasis on the health potential of polyunsaturated fatty acid.
Such fatty acids are known to be essential for human health [18].

FT-IR Analysis: Figure 1 and 2 illustrates the spectrum of oil samples for the local edible oil (before and after frying) with the FT-IR/ Transmission in the range of 4000 to $400 \mathrm{Cm}^{-1}$. The spectrum of oil before frying shows characteristics absorption band associated with common oil. The stretching and bending absorption peaks at 3004 and $723 \mathrm{~cm}^{-1}$ are given by olefinic (cis $=\mathrm{CH}$ ). The strong absorption peaks at around at 2920 to $2870 \mathrm{~cm}^{-1}$ are assigned to $\mathrm{CH}_{3}$ and $\mathrm{CH}_{2}$ asymmetric stretching vibration. Also, the spectra show stretching absorption bands at 1652 $\mathrm{cm}^{-1}$ and $1467 \mathrm{~cm}^{-1}$ which correspond to nonconjugated (cis $\mathrm{C}=\mathrm{C}$ ) bond and $\mathrm{C}-\mathrm{H}$ scissoring respectively, $[19,20]$. While the spectra of fried oil show a sharp stretching absorption bands at 1758 and $1632 \mathrm{~cm}^{-1}$ and broad band at $3450 \mathrm{~cm}^{-1}$ corresponding to $\mathrm{C}=\mathrm{O}$ group and $\mathrm{OH}$ group respectively.

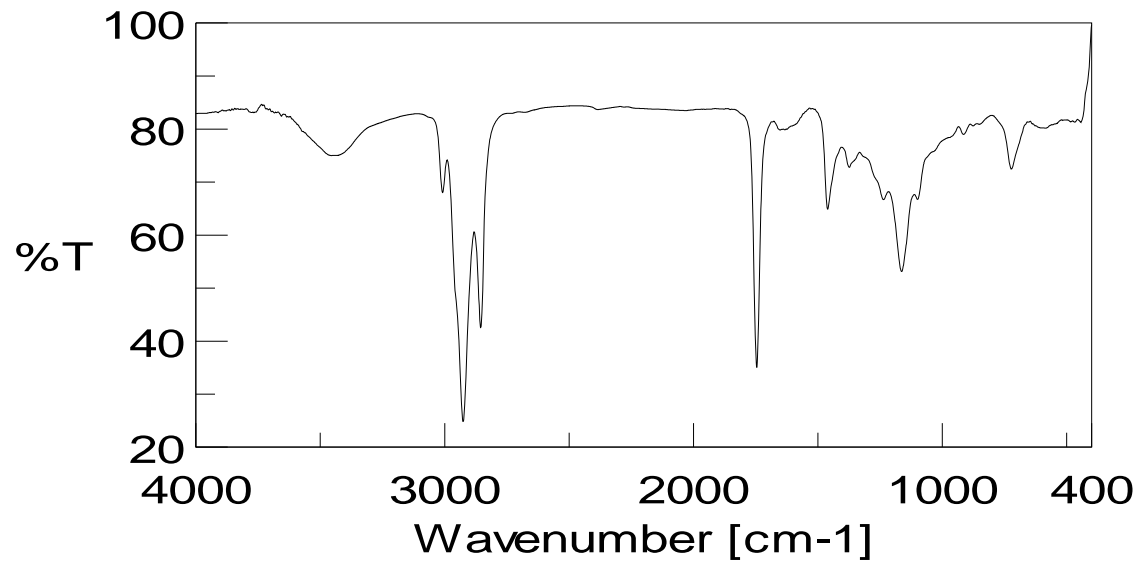

Fig 1: FT-IR of edible oil before frying.

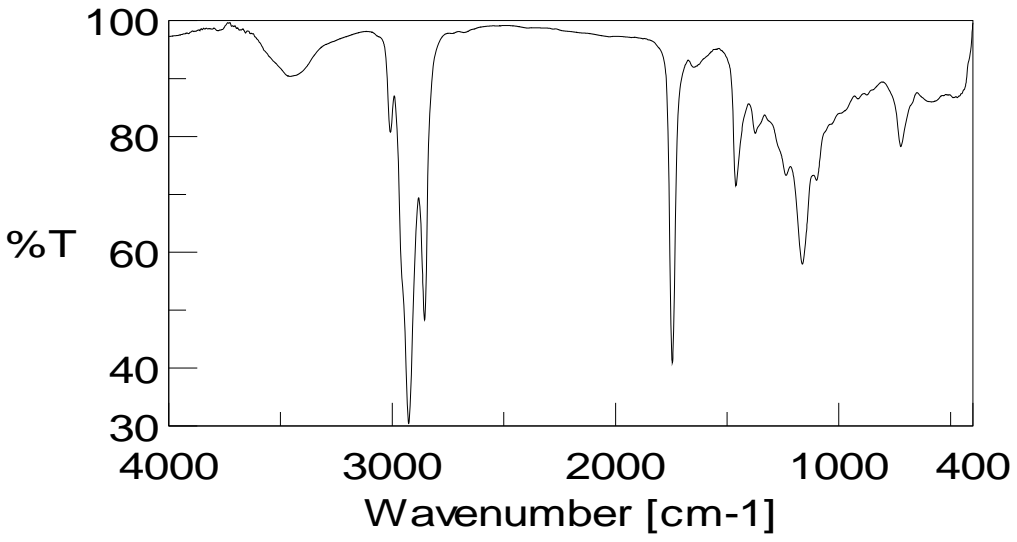

Fig 2: FT-IR of edible oil after frying. 


\section{AGRICULTURE AND BIOLOGY JOURNAL OF NORTH AMERICA}

ISSN Print: 2151-7517, ISSN Online: 2151-7525, doi:10.5251/abjna.2011.2.4.687.692

(C) 2011, ScienceHu $\beta$, http://www.scihub.org/ABJNA

Oxidation Reactions: Oils contain unsaturated fatty acids as shown in table (2) which can react with oxygen to produce unpleasant flavors and odors in the oil. The presence of trace concentrations of metals such as $\mathrm{Ca}, \mathrm{Cu}, \mathrm{Fe}, \mathrm{Zn}$ and $\mathrm{Ni}$ promote oxidation and can significantly reduce the shelf life of an edible oil. Oxidation reaction is illustrated in scheme (1).
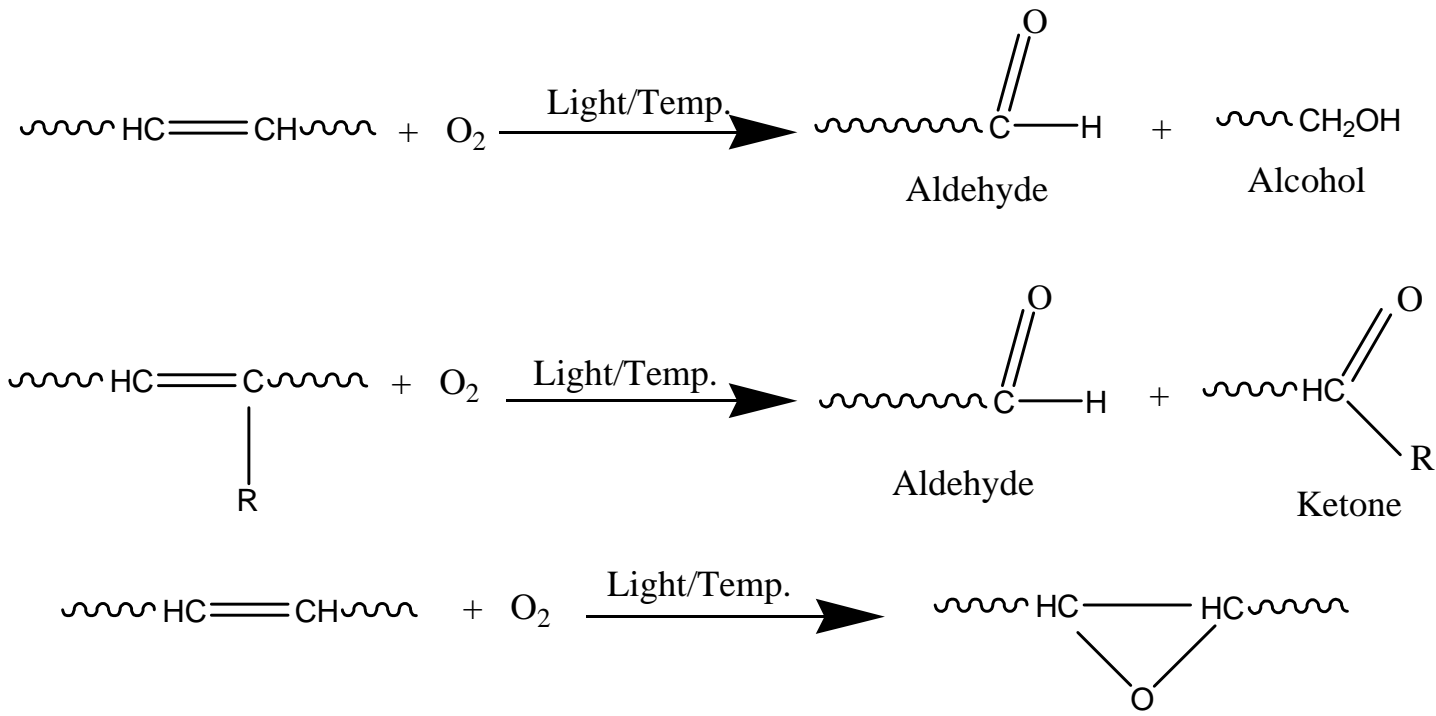

Scheme (1): Oxidation reactions and possible products

The oil is oxidized by air under high temperature resulting in the scission of double bonds leading to increase the reactive centers of fried oil as illustrated in scheme (1). This is confirmed by decreasing the percent of unsaturation fatty acids and iodine value as shown in tables (1 and 2), as well as increasing the intensity of carbonyl groups in FT-IR spectra figure (2).

Determination of trace elements by FAAS: In case of performing the direct analysis of oils without digestion, these techniques may suffer severe interferences from the organic matrix. For this reason it is usual to digest the samples by inorganic acids to form an aqueous clear solution to eliminate the organic matrix [8].

Table 3: Concentration of trace elements in edible oil before and after frying.

\begin{tabular}{|l|l|l|}
\hline \multirow{2}{*}{ Element } & \multicolumn{2}{c|}{ Edible Oil } \\
\cline { 2 - 3 } & \multicolumn{1}{|c|}{ Before Frying } & \multicolumn{1}{c|}{ After Frying } \\
\hline Calcium $(\mathrm{Ca})$ & 67.496 & 117.148 \\
\hline Cupper $(\mathrm{Cu})$ & 0.1167 & 0.184 \\
\hline Iron $(\mathrm{Fe})$ & 0.902 & 1.143 \\
\hline Zinc $(\mathrm{Zn})$ & 0.078 & 0.280 \\
\hline Nickel $(\mathrm{Ni})$ & $\mathrm{BDL}^{*}$ & $\mathrm{BDL}^{*}$ \\
\hline Chrome $(\mathrm{Cr})$ & 0.068 & 0.099 \\
\hline Lead $(\mathrm{Pb})$ & 0.350 & 0.625 \\
\hline
\end{tabular}

* BDL Below detection limit.
It is clear from table (3) that, the concentration of trace elements are increased after frying by about two folds. Where oil before frying has a relatively low concentration of chrome (0.068), iron (0.902), zinc (0.078) and cupper (0.1167), but after frying they become chrome (0.99), iron (1.143), zinc (0.280) and cupper (0.184). On the other hand, calcium have high concentration 67.496 and 117.148 before and after frying respectively. Lead, which have toxicity, showed also a double factor after frying. While nickel was found below the detection limit of the flame atomic absorption spectrometric measurements for both samples (before and after frying). These results can be explained due to the oil is considered as a good solvent for the elements present in food.

CONCLUSION: In conclusion, it may be stated that this study on evaluation of fried edible oil proved that:

1- Edible oil contains mono-unsaturated and poly-unsaturated fatty acids in different amounts. The higher percentages of the linoleic \& oleic and the presence of reasonable amounts of linolenic makes the oil sensitive to oxidation.

2- Trace elements of edible oil before and after frying has been successfully measured using 
FAAS.

3- The use of aqueous standard solutions for calibration and quantification of edible oil samples has been tested and it was proved that can it be successfully applied.

4- Trace elements is increased after frying due to the fact that oil is considered as a good solvent for the elements present in food.

\section{REFERENCES}

1 Khan H., Fida M., Mohammadzai I.U., Khan M. (2007) Estimation of residual nickel and some heavy metals in vanaspatighee, J. Chin. Chem. Soc. 54, 737-741.

2 Matalgyto F.S., Al-Khalifa A.S. (1998) Effect of microwave oven heating on stability of some oil and fats, Arab Gulf J. Sci. Res. 16, 21-40.

3 Naz S., Sheikh H., Siddiqi R., Sayed S.A. (2004) Oxidative stability of olive, corn and soybean oil under different conditions, Food Chem. 88, 253-259.

4 Lankmayr E., Mocak J., Serdt K., Balla B., Wenzl T., Bandoniene D., Gfrerer M., Wagner S. (2004) Chemometrical classification of pumpkin seed oils using UV-Vis, NIR and FTIR spectra, J. Biochem. Biophys. Methods 61, 95-106.

5 Determination of Trace Elements in Edible Oils, Application Note 1024, Solutions for Elemental Analysis, Leeman Labs, Inc.

6 Agilent Technologies publication (2008) Direct Elemental Analysis of Biodiesel by 7500 cx ICP-MS with ORS," 5989-7649EN, April 17.

7 Eunok Choe and David Min (2006) Mechanisms and Factors for Edible Oil Oxidation," Comprehensive Reviews in Food Science and Food Safety, 5, p. 169186.

8 Direct Measurement of Trace Metals in Edible Oils by 7500cx ICP-MS with Octopole Reaction System. Application Note Foods Glenn Woods ICP-MS Specialist Agilent Technologies UK Ltd. Lakeside Business Park Cheadle Royal Cheshire SK8 3GR United Kingdom, 2010.

9 Souza R.M., Mathias B.M., Silveira C.L.P., Aucelio R.Q. (2005) Inductively coupled plasma optical emission spectrometry for trace multi-element determination invegetable oils, margarine and butter after stabilization with propan-1-olandwater, Spectro chim. Acta B 60, 711-715.

10 Davied Firestone (1998) Official Methods and Recommended Practices of the American Oil Chemists Society, Fifth Edition includes all changes 1993-1997, Edition Analytical methods, ChampaigenIllionois, March.

11 AOCS (1996). The official and tentative methods of the American Oil Chemist's Society, AOCS, champaign, IL.

12 IUPAC (1987). International Union of Pure and Applied Chemistry. Standard Methods for the Analysis of Oils and Fats and derivatives, $7^{\text {th }}$ revised and enlarged edn., edited by C. Paquot and A. Haut Fenne, Black Scientific, London.

13 Official and Tentative Methods of the American Oil Chemists Society, Third Edition American Oil Chemists Society. 508 South Sixth Street, Champaigen-Illionois, (1985).

14 Mitruke, B. N., (1984. Gas Chromatographic Application in Microbiology and Medicine, John Wiley and Sons, Inc., New York.

15 Flame Atomic Absorption Spectrometry, Analytical Methods, 1998, Varian Australia, Ptd, Ltd, CAN 004559540, Mulgrave, Vectoria, Australia, Publication No. 85-100009-00.

16 Tan, B. K. and Flingoh. C.H. (1981) Olein and stearin from Malaysian palm oil: Chemical and physical characteristics". PORIM Technology, ISSN, No. 4, 0127-0257.

17 Ajayi I.A. and Adesanwo O. (2009) Comparative Study of the Mineral Element and Fatty Acid Composition of Dacryodes edulis Pulp and Seed" World Journal of Agricultural Sciences 5 (3): 279-283.

18 Mbofung, C.M.F., Gee J.M. and Knight D.J. (1994) Fatty acid profile of some Cameroonian spices. J. Sci. Food Agric., 66: 213-216.

19 Guillen, M.D. and Cabo, N. (1997) Infrared spectroscopy in the study of edible oils and fats. J. Sci. Food and Agriculture, 75: 1-11.

20 Che Man Y. B. and Setiowaty G. (1999) Multivariate calibration of Fourier transform infrared spectra in determining iodine value of palm oil products. Food Chemistry 67: 193-198. 